\title{
Educação, mídia e cultura digital na educação de jovens e adultos
}

\author{
Mariana Pícaro Cerigatto ${ }^{1}$
}

\section{Resumo}

Este artigo desenvolve atividades aplicadas que relacionam mídia e educação, considerando a necessidade da inclusão, de forma mais efetiva, de jovens e adultos na cultura contemporânea. São propostos três eixos de atividades a partir de metodologias específicas para a mídia-educação, pontuadas a partir de uma análise de referências da área. Assim, a contribuição do texto visa subsidiar atividades aplicadas para a EJA, considerando suas diretrizes curriculares. A partir disso, tem-se um caminho para o desenvolvimento de práticas alfabetizadoras que visam à leitura e à produção crítica das imagens, das linguagens da mídia e da contemporaneidade, o que favorece um fazer pedagógico na EJA mais atento às habilidades de engajamento crítico e cidadão na cultura digital e midiática.

Palavras-chave: Mídia-Educação; Educação de Jovens e Adultos; Linguagens Midiáticas.

\section{Education, media and digital culture in youth and adult education}

\section{Abstract}

This article develops applied activities that link media and education, considering the need for more effective inclusion of young people and adults in contemporary culture. Three axes of activities are proposed based on specific methodologies for media literacy, punctuated from an analysis of references in the area. Thus, the text's contribution aims to subsidize activities applied to EJA, considering its curriculum guidelines. From this, there is a path for the development of literacy practices that aim at reading and critical production of images, media languages and contemporaneity, which favors a pedagogical practice in EJA more attentive to the critical engagement skills and citizen in digital and media culture.

Keywords: Media-Education; Youth and Adult Education; Media Languages.

\section{Considerações iniciais}

Os avanços das tecnologias da informação e comunicação nos levam a novas formas de ler e escrever. A partir disso, se discute o significado de ser alfabetizado nos dias de hoje, delineando-se pela dinamicidade das práticas de alfabetização em torno de novas linguagens, novos contextos sociais e culturais.

Ser alfabetizado na sociedade contemporânea ultrapassa saber ler e escrever em meios

\footnotetext{
${ }^{1}$ Universidade Tiradentes, Aracaju-SE, maricerigatto@yahoo.com.br. 
tradicionais. A cultura digital, midiática e participativa ${ }^{2}$ expande as possibilidades de aprendizado, trazendo novos olhares aos processos de ensino e aprendizagem, assim como desafios.

No ambiente digital e midiático, temos uma variedade de textos que surge em um ambiente em que qualquer pessoa pode criar conteúdos. Para Anstey e Bull (2007), um indivíduo "multiliterado" é flexível e compreende que a alfabetização é dinâmica e não estática, e se modifica diante as transformações sociais, culturais e tecnológicas.

Essas transformações ganham ainda mais relevância no contexto de educação de jovens e adultos, e apontam a necessidade de fortalecer a "educação continuada ao longo da vida", que é um movimento crescente, especialmente nas sociedades pós-industriais, que vivem em meio a uma crescente velocidade de produção de novos conhecimentos e difusão de informações, conforme observam Haddad e Di Pierro (2000). A formação ao longo da vida atinge diretamente a vida da população adulta e acaba por se tornar um valor fundamental na vida dos indivíduos e também requisito para o desenvolvimento de países globalizados e competitivos. Neste sentido, o cenário contemporâneo exige cada vez mais uma formação atualizada em diversos âmbitos.

Ao considerar o ambiente dinâmico da internet, em que uma nova cultura se molda com a utilização de novas mídias e tecnologias, surgem necessidades de apropriação dessa cultura e da inserção de todos os indivíduos nesta esfera digital, para a participação e inclusão mais efetiva de novas práticas de cidadania, comunicação, difusão e apropriação da informação e conhecimento etc.

Para que jovens e adultos sejam incluídos de forma mais efetiva nesta cultura participativa há de se promover habilidades de leitura e escrita críticas, que permitem participar da sociedade como um cidadão ativo, de maneira que seja possível compreender a tecnologia e seus textos dentro de uma consciência mais crítica e reflexiva, aproveitando essas habilidades para a área profissional, pessoal etc.

Cabe ainda aqui fazer a relação entre a inclusão na cultura participativa com princípios

\footnotetext{
2 "Cultura participativa" é uma expressão adotada pelo estudioso de cultura digital Henry Jenkins (2009), que usa o termo para fazer referência à adesão popular da internet nos últimos anos, e às novas formas de interação e participação que os ambientes online têm promovido.
} 
observados na obra de Freire (1980), que propõe uma "educação popular", com base na libertação dos indivíduos por meio do desenvolvimento de posturas e consciência críticas, que podem levar ações diferenciadas, uma aproximação mais crítica com a realidade. Essa emancipação que menciona o autor pode ser relacionada na contemporaneidade com a capacidade de se engajar e participar ativamente, e criticamente junto à cultura midiática. Saber ler e escrever com as novas tecnologias, saber se posicionar frente às mensagens tanto das novas e velhas mídias, pode reforçar os ensinamentos de Freire (1980), que defende uma criticidade consciente capaz de emancipar os indivíduos. Ampliando a capacidade de reflexão sobre a mídia, pode-se desenvolver indivíduos que melhor se posicionam e saibam identificar estereótipos sociais reproduzidos pelos meios de comunicação.

Pode-se dizer, ainda, que as práticas de alfabetização midiática e digital se reforçam no cenário de educação de jovens, adultos e idosos. Diferentemente dos chamados "nativos digitais" - uma geração de crianças e adolescentes que já nascem em meio às novas tecnologias e no bojo dessa cultura midiática - os jovens, adultos e idosos precisam se apropriar das linguagens e tecnologias para exercício efetivo da cidadania, desenvolvimento profissional etc. No entanto, essa formação não deve se calcar apenas a uma prática que vise à instrumentalização da tecnologia e da mídia, sem considerar um engajamento mais crítico e responsável.

Ao avançar quanto a uma perspectiva limitada à instrumentalização, o estudo das mídias, da cultura digital e suas linguagens pode propiciar o desenvolvimento de habilidades críticas quanto às representações que as mídias fazem sobre diversos assuntos. Além disso, jovens, adultos e idosos podem ser alfabetizados também com as linguagens que vão além do verbal, obtendo mais conhecimento para saber ler novos textos e escrever também usando essas novas linguagens - que incluem imagens, memes etc. Assim, a proposta é incluir esse público de forma mais efetiva e autônoma no universo cultural das mídias, suas linguagens e tecnologias.

Os cursos de Educação de Jovens e Adultos (EJA), geralmente, voltam-se a estudantes trabalhadores, com maior experiência de vida, sendo que muitos deles tiveram que abandonar os estudos em certas fases da vida (BRASIL, 2013). As bases curriculares nacionais defendem a integração desses indivíduos ao cenário de cultura e sociedade contemporânea, considerando o exercício de sua cidadania. São valorizados conteúdos significativos para os jovens e adultos, 
atividades e vivências socializadoras, culturais etc., que sejam geradoras de enriquecimento de seu percurso formativo.

Neste sentido, é muito propício trabalhar com a questão das mídias e da cultura digital com este público, considerando que essas fazem parte do cotidiano desses sujeitos. No entanto, conforme relata Kirsch (2010), em uma experiência com as mídias no ensino de EJA, a maioria dos alunos apenas enxergava as mídias (televisão, internet etc.) dentro de uma perspectiva de entretenimento, lazer e distração.

Assim, considera-se importante salientar que o trabalho com os conteúdos trazidos pelas mídias e as tecnologias exige uma postura equilibrada do professor. De acordo com Freire (2000), divinizar ou diabolizar a tecnologia ou a ciência é uma maneira bastante negativa e perigosa de pensar errado. Neste mesmo sentido, Green e Hannon (2007) analisam que os professores, ao tratarem desse assunto em sala de aula, tendem a ter posturas extremistas. A abordagem do "pânico moral" considera que a cultura trazida pelas tecnologias e cultura da mídia é uma degeneração que deve ser combatida. Os mesmos autores ainda evidenciam o outro extremo, apontando aqueles que têm uma "fé cega" (para quem a simples presença das tecnologias já é algo revolucionário e positivo).

No lugar de enfatizar os efeitos negativos que as tecnologias e mídias causam, deve-se valorizar a compreensão e suas implicações sociais, culturais e educacionais. No entanto, constata-se que a postura adepta ao "pânico moral" (que tende a condenar o uso de mídias e tecnologias) é ainda bastante frequente no ambiente escolar.

Outra questão pertinente se refere à maneira como se trabalha com as mídias e tecnologias em sala de aula, e, mais uma vez, aqui se reforça que a abordagem deve ir além de um mero uso instrumental. A cultura digital traz uma nova dinamicidade à nossa sociedade e aos processos educacionais. Apesar disso, o que se vê em sala de aula é ainda o uso de mídias e tecnologias longe da lógica participativa que a cultura digital promove. E ainda, o uso é, muitas vezes, apenas de caráter instrumental. Limitar-se à transmissão de conteúdos e usar as mídias e suas linguagens apenas como recursos para apoiar conteúdos didáticos têm sido posturas mais comuns em sala de aula, o que acaba desprezando toda a possibilidade interativa, participativa e criativa que o universo da cultura digital engloba, assim como a atual cultura midiática. 
Quando se trata de inserir as mídias e seus conteúdos em sala de aula, há ainda pouco respaldo metodológico. No entanto, há caminhos para a inserção dessa temática de forma que esteja mais calcada em habilidades críticas e reflexivas por meio de uma área reconhecida internacionalmente como media literacy, ou então, mídia-educação.

Neste trabalho, que tem como objeto de estudo a relação entre mídia e educação e o desenvolvimento de práticas alfabetizadoras no contexto de mídia digital, apresenta-se uma metodologia para o desenvolvimento da mídia-educação na escolarização de jovens e adultos, considerando técnicas pedagógicas e referenciais para práticas bem fundamentadas, a partir de um estudo de cunho teórico, e também experiências anteriormente já realizadas. Enfatizase o acesso, uso e a apropriação crítica da tecnologia, mídia e suas linguagens por jovens e adultos. As atividades visam à leitura crítica de conteúdos como reportagens, memes, imagens no contexto de mídia, e também o desenvolvimento de habilidades de multimodalidade (o trabalho com diferentes linguagens e plataformas) e a produção midiática mais engajada e responsável.

Reforça-se ainda a importância desta proposta didática no âmbito da escolarização de jovens e adultos, visto que o atendimento educacional a essa fatia da população nem sempre tem sido colocado no mesmo patamar de outros níveis de ensino e grupos etários. Conforme analisam Haddad e Di Pierro (2000), o ensino fundamental de jovens e adultos tem, historicamente, perdido espaço enquanto atendimento educacional público de caráter universal.

Neste sentido, espera-se que a proposta aqui apresentada reforce a importância de se fortalecer práticas alfabetizadoras voltadas para esse público no contexto da escolarização, e que as práticas de inclusão digital e midiática contemporâneas possam ser colocadas para extensas parcelas da população, diminuindo as desigualdades.

A proposta, ainda, visa contribuir para a formação de uma visão crítica sobre a mídia e seus conteúdos em sala de aula, evitando limitar-se ao mero uso instrumental dos meios de comunicação.

\section{Educação para a mídia: principais fundamentos}

O conceito de media literacy se desenvolveu de variadas formas em diferentes partes do 
mundo, mas aqui se combate o viés instrumentalista da educação para a mídia - ou seja, a abordagem que define media literacy apenas considerando a mídia como ferramenta para transmissão de conteúdo. A mídia-educação é uma área interdisciplinar do conhecimento que se preocupa em desenvolver formas de ensinar e aprender aspectos relevantes da inserção dos meios de comunicação na sociedade. Assim, a "literacia em mídia" é o resultado esperado dessas ações pedagógicas, que envolvem, necessariamente, a compreensão crítica e a participação ativa (SIQUEIRA, 2014). A cultura, a crítica, a criação e a cidadania são os "4C" da mídia-educação, conforme desenvolve Fantin (2014).

Assim, atividades de mídia-educação estão relacionadas com a cultura pelo fato de ampliar e diversificar os repertórios culturais. Essas ações devem considerar habilidades de leitura crítica (análise, reflexão e avaliação de conteúdos) e oportunizar a criação, o exercício da criatividade, da expressão, da comunicação e da construção de conhecimentos.

A educação para a mídia é fundamental para garantir as necessidades de um novo letramento, e está de acordo com os anseios das multiliteracias (BUCKINGHAM, 2019). A educação para a mídia é também essencial nos processos de socialização de qualquer geração, pois a media literacy é uma concepção de educação ao longo da vida, é imprescindível para a produção, reprodução e transmissão da cultura (BÉVORT; BELLONI, 2009).

A mídia-educação segue sendo desenvolvida com diversos vieses. Aqui, a proposta se baseia no trabalho de professores ingleses, tais como Buckingham $(2003,2008,2019)$ e Lusted (1991), que vêm desenvolvendo já há alguns anos práticas pedagógicas calcadas em conceitoschave para o aprendizado das mídias, assim como técnicas pedagógicas específicas, visto que a Inglaterra é um dos países que desenvolveu uma política pública de educação para a mídia. Pesquisadores brasileiros, como Siqueira (2014), Fantin (2014), Almeida (2009), têm dado contribuições importantes na mesma perspectiva.

O aprendizado da cultura midiática e digital recorre a quatro conceitos-chave mais comuns, conforme explana Buckingham (2003), e trazem uma significativa contribuição metodológica ao processo de leitura e produção críticas, conforme se explana a seguir:

Linguagens midiáticas: Conceito-chave que explora a linguagem dos meios de comunicação. A escolha de um elemento dessa linguagem e a combinação entre linguagens diferentes (imagem, som, texto impresso) causam certos efeitos estéticos, ou demonstram 
"pistas" para avaliar a posição ideológica do autor das mensagens. Neste exame, é importante observar as convenções e os códigos, ou seja, formas de usar a linguagem na propaganda, nas novelas etc., assim como estereótipos que se tornam familiares e largamente aceitos.

Instituições de mídia: Aqui entra a reflexão e análise de como os proprietários das empresas de comunicação dão forma às mensagens para atingir interesses econômicos, políticos etc. O objetivo é a conscientização e o reconhecimento de que tudo que é disseminado pelas mídias sofre fortes influências de quem produz - seja o indivíduo, grupos de pessoas ou empresas de comunicação e outros segmentos.

Audiência: Conceito-chave que busca compreender como as mídias e empresas estão empenhadas em atingir determinadas audiências, e como as mensagens refletem valores desses públicos.

Representação: Aprender a avaliar criticamente o modo como os recursos da linguagem, assim como a busca pela audiência e a defesa por certos valores resultam em estereótipos e visões de mundo transmitidos pela mídia.

Ao longo dos anos, tenho trabalhado com esses conceitos em atividades de educação para a mídia envolvendo adolescentes, jovens e adultos. Essas vivências podem ser melhor sistematizadas considerando as seguintes técnicas específicas para o trabalho com a mídiaeducação, também baseadas em Buckingham (2003, 2008):

Análise textual e contextual: - técnica que consiste em fazer do familiar, estranho, a fim de encorajar a formação de um ponto de vista a partir de uma reflexão. Estuda a linguagem da mídia mais a fundo, a fim de identificar padrões e valores. Nessa técnica, podemos analisar os recursos técnicos e estéticos empregados, recursos que criam os apelos e ajudam a manter determinado público cativo.

Estudo de caso: Conhecer o processo de produção: como se define o público-alvo, como se constrói a mensagem, onde se insere o marketing e publicidade e que respostas gera na recepção.

Tradução: São as mudanças que ocorrem quando um conteúdo é tratado em mídias diferentes e em gêneros/formatos diferentes, considerando também audiências diferentes.

Simulação e produção: Técnica que consiste em explorar situações-problema da cultura midiática para serem resolvidas. 
Após essa explanação, segue a proposta de um trabalho prático usando os conceitoschave e técnicas pedagógicas na Educação de Jovens e Adultos (EJA), considerando a faixa etária e conteúdos midiáticos que trazem assuntos relacionados ao contexto desse público.

\section{Proposta de educação para a mídia na EJA}

Nesta proposta, dividem-se as atividades em três eixos/tipos, considerando as atuais diretrizes curriculares da EJA. As atividades, de maneira geral, se atentam para a importância de estimular a reflexão e a análise aprofundada em relação ao conteúdo e à multiplicidade de ofertas midiáticas e digitais, focando o desenvolvimento da criticidade. A intenção é envolver os sujeitos com o universo da cultura midiática e digital, dentro de uma perspectiva de cidadania consciente e participativa.

A partir da centralidade que as mídias e suas linguagens passam a ocupar na vida de jovens e adultos, a proposta prevê três principais eixos:

Eixo1 - Atividades com as linguagens midiáticas: Jovens e adultos tomam decisões e constroem visões de mundo desde a infância, e a falta de escolarização é uma desvantagem para que esses sujeitos se tornem indivíduos capazes de refletir criticamente sobre a maneira como a mídia tem influenciado em seus gostos e fomentado visões de mundo e estereótipos, muitas vezes, aceitos como "naturais".

A escola pode trazer à tona esses conteúdos que mais circulam entre esse público, utilizando os conceitos-chave de linguagem midiática, instituições de mídia, audiência e representação.

A seguir, um exemplo de uma reportagem que teve muita repercussão, voltado para o público adulto, sendo um caminho para se trabalhar a leitura crítica e refletir sobre questões de gênero e os papéis que são fortemente associados às mulheres pelas mídias: 
Figura 1 - Página com manchete principal da reportagem publicada pela revista Veja, com o título "Bela, recatada e do lar"

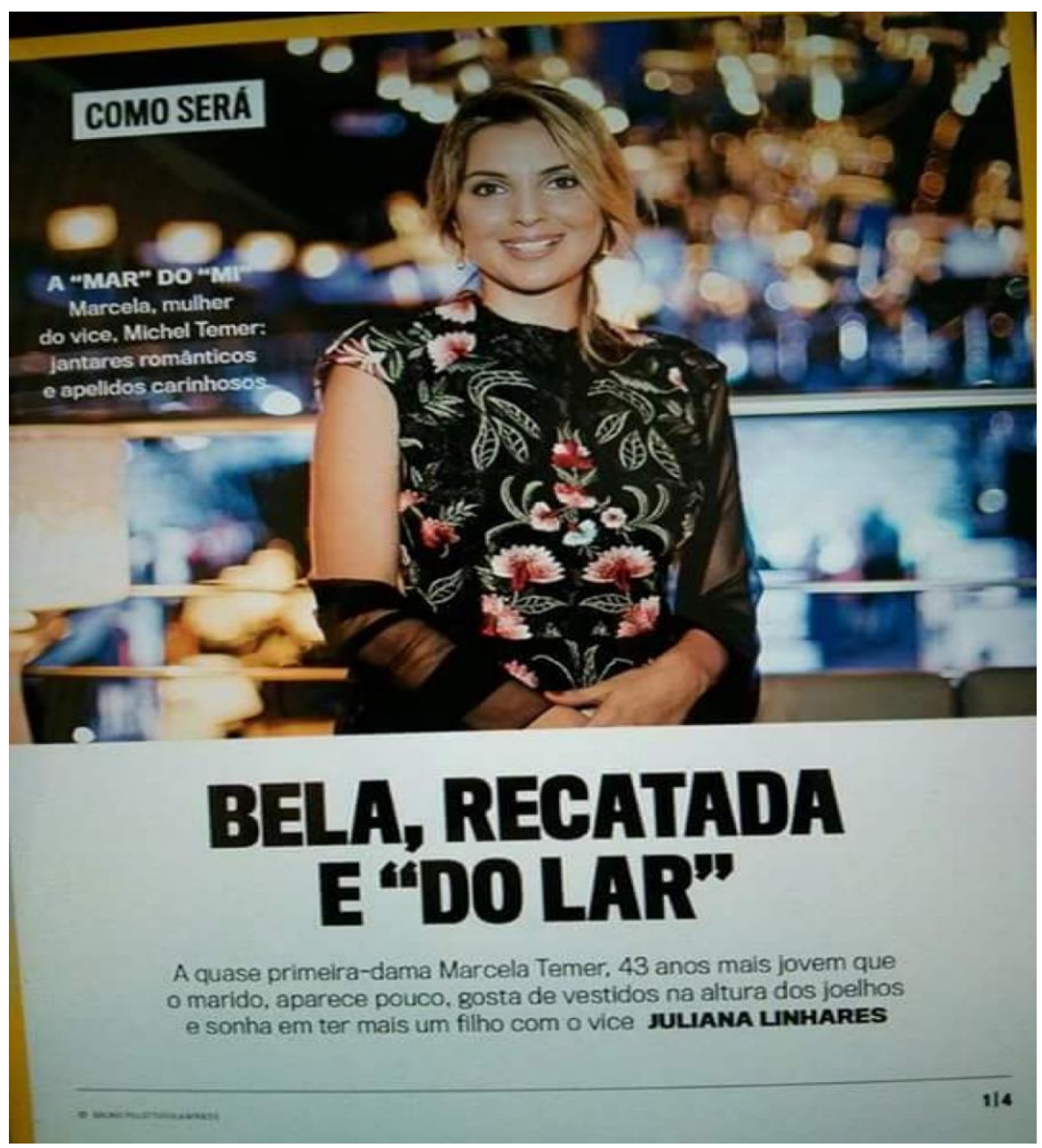

Fonte: Reportagem da revista Veja (edição de 18 de abril de 2016) ${ }^{3}$.

Em 18 de abril de 2016, a revista Veja trouxe uma matéria com a primeira dama Marcela Temer, a então atual esposa do ex-presidente do Brasil, Michel Temer, com a manchete "Bela, recatada e do lar". No texto, descreve-se o perfil de Marcela, com evidência na linha fina para o fato da primeira dama gostar de vestidos na altura dos joelhos e "aparecer pouco". Ao final do texto, a jornalista conclui que "Michel Temer é um homem de sorte".

Através dos conceitos-chave pode-se compreender melhor como tais produções têm representado a mulher e outras questões de gênero, muitas vezes de forma estereotipada. Esse assunto é propício para ser trabalhado junto à EJA, já que se trata de uma revista de circulação

\footnotetext{
${ }^{3}$ Disponível em: https://www.opopular.com.br/noticias/magazine/bela-recatada-e-do-lar-entenda-a-frase-que-invadiua-internet-1.1072697. Acesso em: 20 de março de 2020.
}

Periódico Horizontes - USF - Itatiba, SP - Brasil - e020046 
nacional, muito lida especialmente pelo público adulto.

Para analisar os elementos da linguagem, usamos a técnica de análise textual e o conceito-chave de linguagens midiáticas, vistos em Buckingham (2003). Quais são os elementos da linguagem que dão formato à manchete? Pode-se dizer que Marcela, a ex-primeira dama, aparece em primeiro plano na foto, que mostra parte de seu corpo e vestimenta, e também em uma pose um tanto discreta. O fundo é desfocado, o que evidencia ainda mais a mulher na foto. O título realça os adjetivos bela, recatada e do lar.

A segunda etapa do trabalho parte para a análise contextual - o que esses elementos estão representando, como são postos, e qual ideia eles difundem sobre a audiência que pretendem atingir? Ou seja, Marcela, a ex-primeira dama, é colocada pela reportagem em uma espécie de "altar", de modelo a ser seguida. A foto valoriza a vestimenta de cor preta, com desenhos florais e um lenço cobre parte dos braços. Marcela aparece com maquiagem discreta e cabelo preso. Percebe-se que a linguagem visual conversa diretamente com a linguagem verbal - no caso, com os adjetivos postos na manchete. A pose de Marcela, somada às suas vestimentas escuras, fechadas, remetem a uma moça "recatada". A beleza de Marcela é evidenciada pelo adjetivo "bela". Soma-se à essa construção a expressão "do lar". Assim, o efeito da mensagem midiática aponta para o fato de que Marcela é colocada em evidência, assim como seu estilo, modo de se portar e se vestir são transmitidos como referências, reforçadas pelas palavras do título da reportagem. Forma-se, assim, um padrão a ser seguido, colocado de maneira supervalorizado em uma das matérias jornalísticas principais de uma revista de alta circulação nacional. Temos, então, um estereótipo. Aqui já estamos trabalhando com o conceito de representação, que é a formação de um ponto de vista a partir de recortes e generalizações feitas pelas mídias, conforme reforça Siqueira (2014).

É cabível ainda a análise da audiência e da instituição de mídia, conforme sugere Buckingham (2003). No caso, o perfil de audiência da revista Veja se volta a um público de classe média e classe média alta - no entanto, a revista também é lida em muitos contextos por classes menos abastadas. O público "potencial" da revista, no entanto, é um público de nível superior e intelectualizado. De maneira geral, pode-se dizer que a mídia, ao transmitir um estereótipo, faz também isso de acordo com a noção de que se tem da sua "audiência ideal", e dos valores compartilhados por esta, conforme ressaltam autores como Siqueira (2014) e Almeida (2009). 
Pode-se dizer que a Veja, sendo uma revista mais associada aos "adultos", faz uma representação voltada para atingir esse público.

A análise do conceito-chave de instituição de mídia nos leva a crer que a revista Veja possui valores ideológicos, políticos e econômicos. Neste caso, Veja revela seu posicionamento político, ao fazer uma reportagem totalmente favorável à ex-primeira dama, apenas falando dos aspectos positivos relacionados a ela. Uma importante "propaganda ideológica" para a atual primeira dama da época, que também beneficia o presidente à época, Michel Temer, já que, na reportagem, Marcela sublinha as qualidades do então marido.

A revista Veja, enquanto instituição de mídia, também demonstra seu posicionamento em relação ao papel que a mulher deveria cumprir em sociedade. Ao colocar o perfil de Marcela em destaque, e associar ao título "Bela, recatada e do lar", a revista, mesmo que indiretamente, revela qual deveria ser o papel exercido pela mulher em sociedade - ela deve ser como Marcela - bonita, discreta, tímida e ligada aos afazeres domésticos.

Essa reportagem ganhou grande repercussão além das páginas da revista - foi motivo para postagens, sátiras e memes em redes sociais. O estereótipo de mulher bela, recatada e do lar incentivou mulheres de várias classes sociais e faixas etárias a postarem fotos satirizando e ironizando o modelo proposto pela revista. Muitas das fotos traziam um modelo totalmente oposto àquele disseminado pela revista.

Assim, ao fazer uma análise crítica das mensagens da mídia, nos afastamos emocionalmente do texto e aprendemos a vê-lo por dentro e por fora, para depois sustentar uma opinião informada sobre a mensagem (HALL; WHANNEL, 1964; BUCKINGHAM, 2003; LUSTED, 1991). A avaliação crítica do conteúdo midiático pode partir, assim, da análise de como os recursos de linguagem criam significados, como uma fonte midiática "emprega um código e produz uma 'mensagem'; em outro momento determinado, a 'mensagem' desemboca na estrutura das práticas sociais pela via de sua decodificação" (HALL, 2003, p.390).

Ao fazer o percurso de análise crítica da mídia, percebemos que muitas das representações geradas sobre o papel da mulher estão condicionadas a características da audiência e dos valores e interesses da instituição de mídia.

É possível levar a mesma leitura crítica para uma propaganda de cerveja, que possui um público que passa pelo jovem e adulto: 
Figura 2 - Propaganda de cerveja Antarctica, com a atriz Juliana Paes.

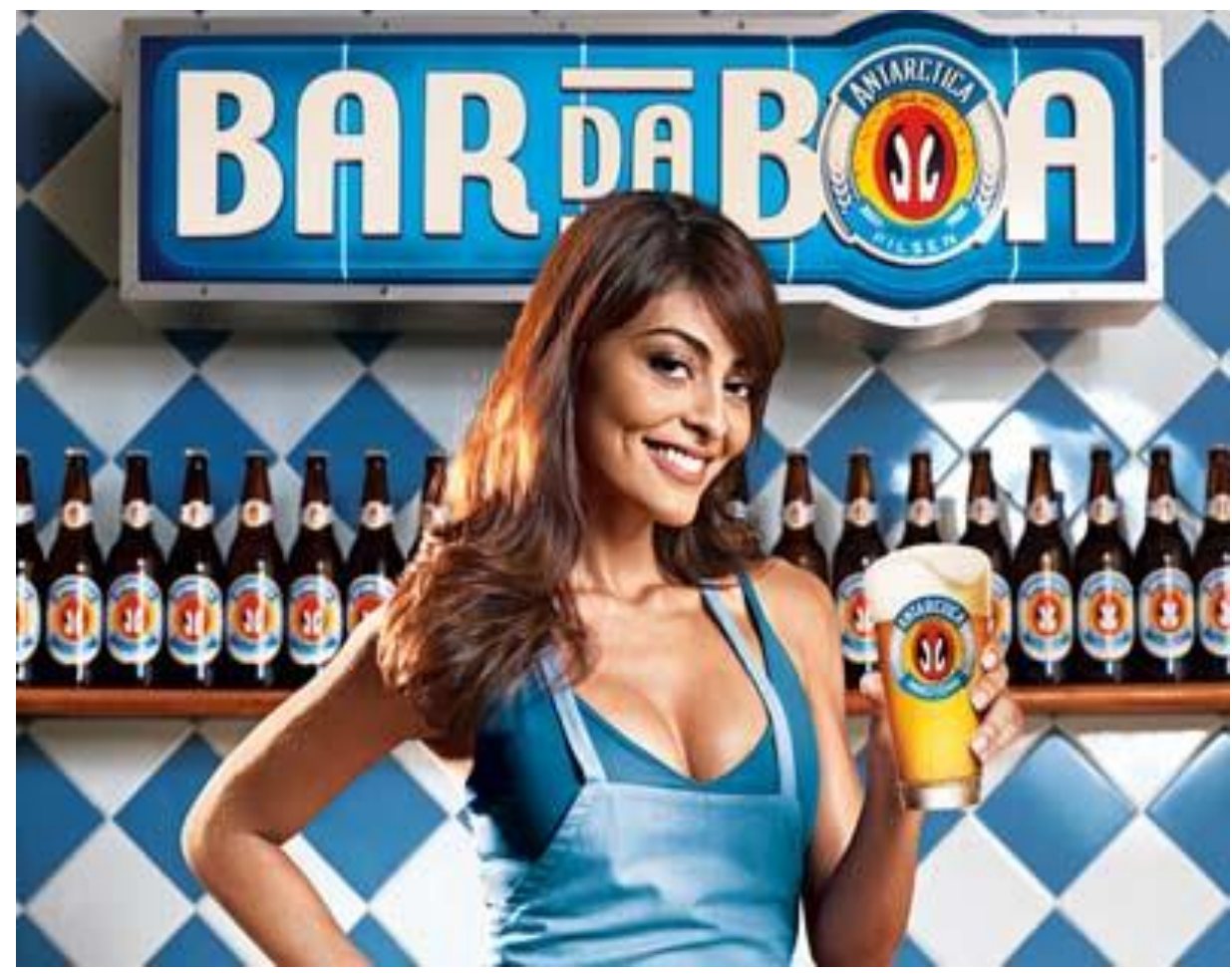

Fonte: Imagem da campanha da Antarctica ${ }^{4}$.

Nesta peça, a questão da mulher também é trazida à tona e, mais uma vez, recorre-se às técnicas de análise textual e contextual. Tem-se a imagem "conversando" com o texto verbal: há a referência da cor azul em toda a imagem, inclusive na atriz Juliana Paes, o que reforça a cor que também integra parte do logotipo da marca. A atriz é mostrada em primeiro plano, logo atrás estão as cervejas e a placa "Bar da Boa", sendo a vogal "o" da palavra "boa" substituído pela logomarca da Antarctica. A pose dela evidencia a cerveja. A modelo também apresenta decote na blusa e está vestida com um avental de cozinha.

Ao desconstruir a peça, vemos mensagens bastante representativas, de acordo com os conceitos delimitados em Buckingham (2008): Juliana Paes, sendo uma atriz prestigiada em nossa sociedade, possui também um corpo elogiado e em evidência em capas de revista, em telenovelas etc. O fato de Juliana estar com um avental se associa a um papel: de que ela está ali para servir, no caso, um homem. A pose da atriz e seu decote valorizam seu corpo e o colocam

\footnotetext{
${ }^{4}$ Disponível em: http://etilicos.com/as-dez-propagandas-mais-famosas-de-cerveja/. Acesso em: 13 de março de 2020.
} 
em evidência. E ainda, o slogan "bar da boa" remete também a Juliana. A mulher, neste caso, por meio dos elementos da linguagem verbal e visual, é posta no papel de servir, ela é a "boa", o que representa também um apelo sexual.

Assim, pode-se considerar que a marca enxerga as mulheres dentro desse papel - de ser submissa sexual do homem e servi-lo. Esse é um posicionamento da marca, esses são os valores em relação à mulher colocados nesta mensagem midiática.

Ao fazer essa desconstrução, tem-se a oportunidade de se distanciar emocionalmente e fazer análises mais racionais, entendendo um pouco do contexto da indústria midiática e de consumo; de que existe uma audiência a atingir e existe um emissor por trás de cada mensagem de comunicação, que usa uma linguagem para representar uma determinada audiência (LUSTED, 1991).

O professor pode questionar esses estereótipos encontrados no anúncio e na reportagem junto aos alunos da EJA, fazendo-os refletir sobre os estereótipos presentes em diversos conteúdos de mídia consumidos por eles, e como essas mensagens funcionam em seu contexto social.

Eixo 2 - Atividades com multimodalidades e transmídia: Aqui, a proposta, mais uma vez pensada para a EJA, é que o professor compare diferentes narrativas por meio de diferentes mídias e desenvolva o senso crítico de perceber como cada mídia "conta" uma história. Em tempos de cultura digital, há vários textos que circulam por meio das mais diversas mídias e dispositivos.

Pode-se pedir para que os alunos, a partir da reportagem com a ex-primeira dama Marcela Temer, comparem como a mensagem da matéria jornalística repercutiu para as redes sociais e a internet, sendo que o estereótipo criado pela revista se desdobrou em mensagens críticas, que contestam o padrão de mulher "bela, recatada e do lar".

Ao trabalhar com as multimodalidades, ou seja, as diferentes maneiras de representar um mesmo conteúdo por meio de linguagens diferentes (escrita, audiovisual etc.), desenvolvemos a habilidade transmídia, que é a capacidade de transitar por mídias diferentes, identificando como cada linguagem moldou o conteúdo.

O objetivo é que os alunos reflitam mudanças na linguagem e mesmo no conteúdo posto em diferentes formatos: 
Figura 3: Meme "Bela, recatada e do lar"

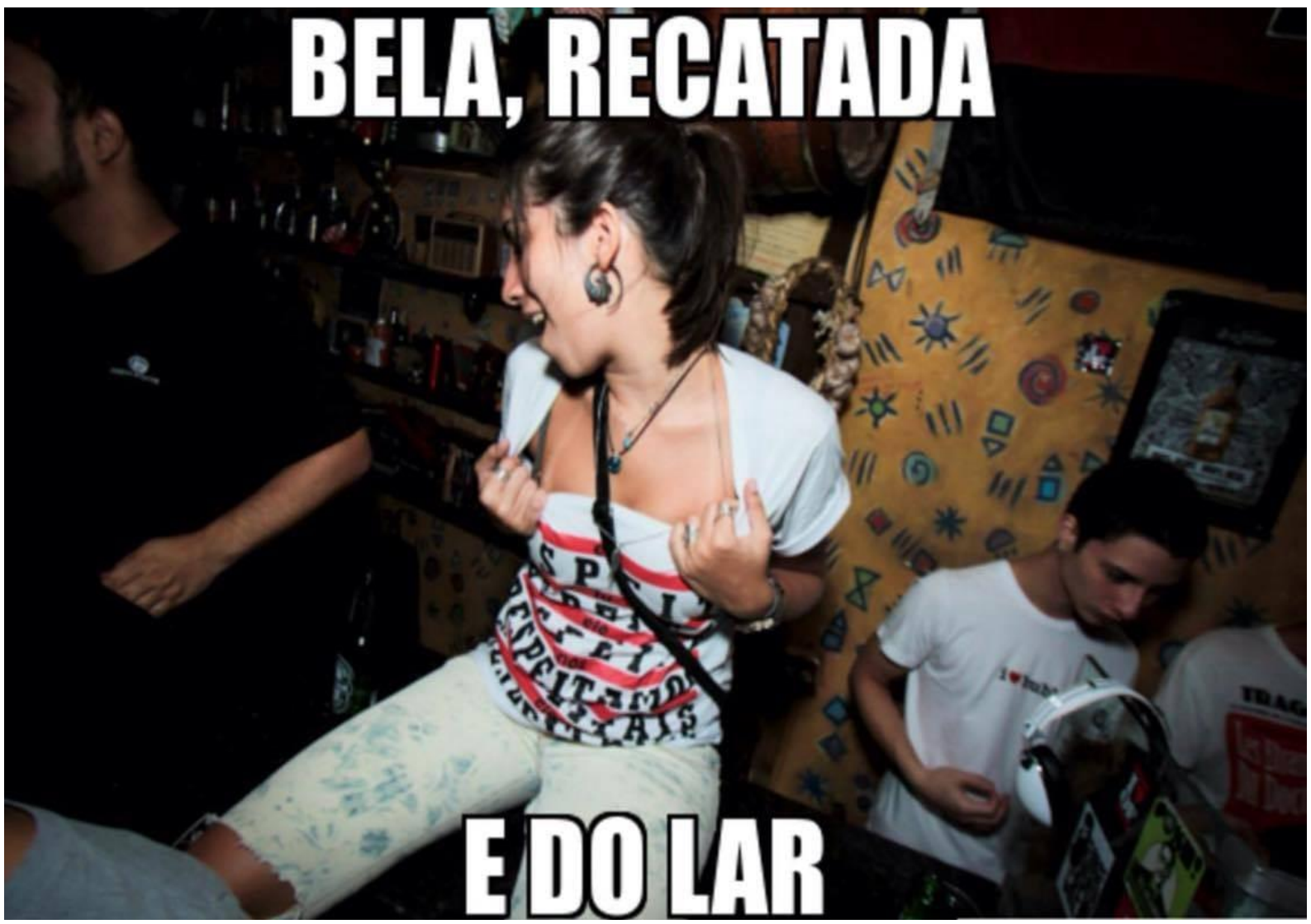

Fonte: Meme "Bela, Recatada e do Lar" do site Catraca Livre5.

${ }^{5}$ Disponível em: https://catracalivre.com.br/entretenimento/tumblr-bela-recatada-e-do-lar-reune-memes-incriveis-emresposta-materia-da-revista-veja/. Acesso em: 10 de março de 2020. 
Figura 4 - Meme "Bela, recatada e do lar"

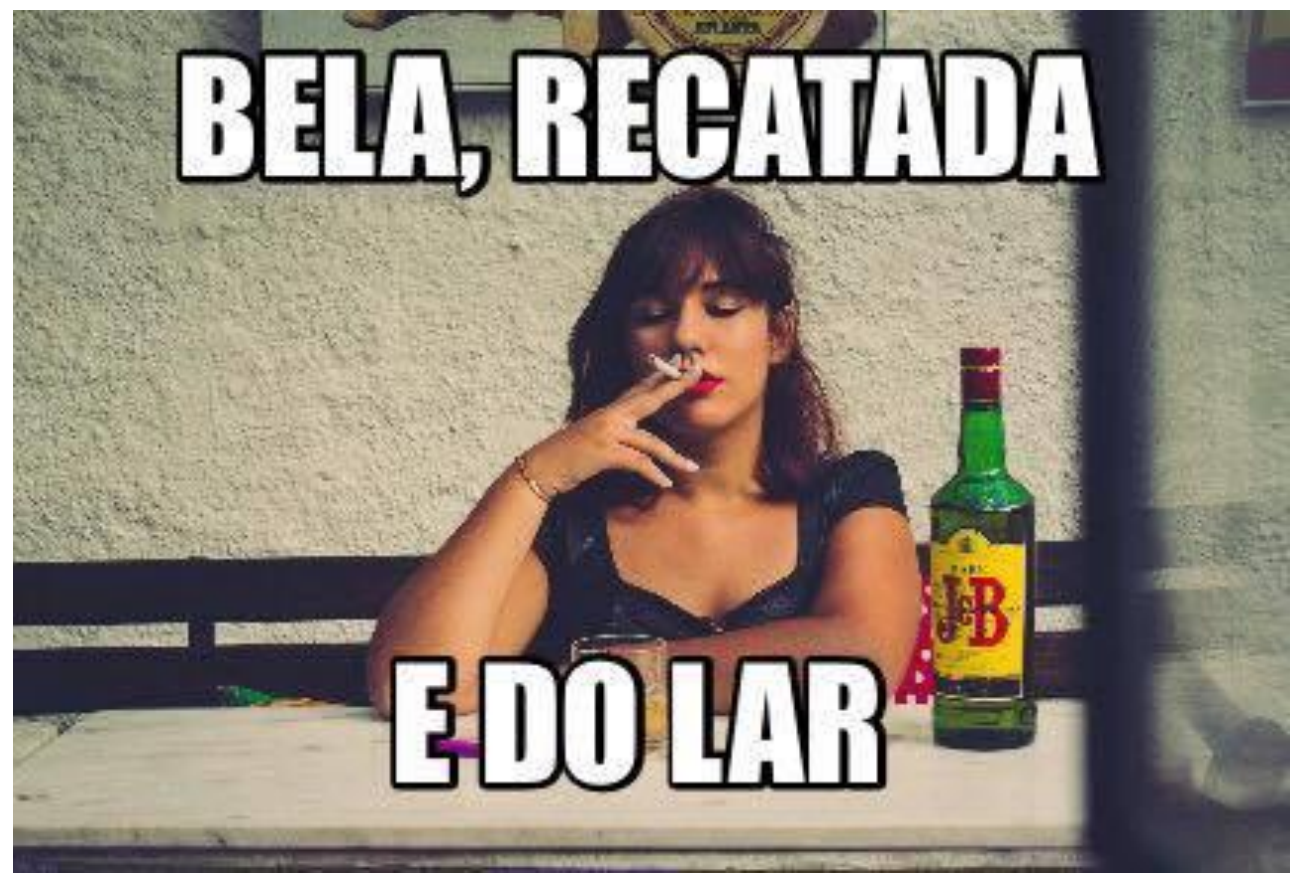

Fonte: Meme “Bela, Recatada e do Lar" do site Super Ela ${ }^{6}$.

O uso de "memes" é uma característica marcante do cenário de cultura digital e midiática. Essas montagens revelam práticas de "remix" que são combinações entre textos diferentes, que demonstram a habilidade de usuário da web com as tecnologias digitais (LEMOS, 2015). No ambiente de mídias digitais, cresce o leque de acesso aos mais variados textos, agora produzidos por cidadãos comuns, os chamados "remixers", que criam novos conteúdos seguindo o movimento copyleft (LEMOS, 2015).

Criado em 1976 por Richard Dawkins - biólogo e escritor - o termo "meme" surgiu com intuito de explicar o fenômeno de replicação de certas informações e ideias em nossa sociedade, conforme revisam Trevisan e Goethel (2015). O processo de propagação dos memes acontece através da imitação. Assim, o "meme" se refere ao potencial de replicar algo presente no cotidiano, sendo que "[...] é a imitação não exata do objeto imitado que o torna único, afinal o indivíduo tentará imitar através de uma representação do objeto imitado, impondo assim seus maneirismos e suas limitações" (TREVISAN; GOETHEL, 2015, p.2).

\footnotetext{
${ }^{6}$ Disponível em: https://superela.com/2016/04/20/os-melhores-memes-das-nossas-bela-recatada-e-do-lar/. Acesso em: 4 de março de 2020.
} 
Atualmente, o meme ganhou muita popularidade. As redes sociais digitais se apropriaram do termo, sendo que um meme neste contexto diz respeito a uma junção de imagens advindas da cultura popular combinada a frases que refletem pensamentos individuais ou coletivos, sejam eles com fins cômicos, políticos, entre outros. A facilidade de os usuários produzirem seus próprios memes, motivados pelo fator interatividade, impulsionou a utilização deles como forma de linguagem muito comum nas mídias sociais.

Os memes fazem parte da vida cotidiana de quem acessa à internet - jovens, adultos e idosos compartilham e acessam esses conteúdos. Os memes das figuras 3 e 4 remetem aos desdobramentos da reportagem da revista Veja com Marcela Temer.

Com base na técnica pedagógica de tradução da mídia-educação, pode-se analisar junto aos alunos da EJA como a internet "reconta" e recria ideias e histórias compartilhadas pelas mídias tradicionais. Quais são as mudanças vistas?

No caso dos memes aqui expostos, a proposta é fazer uma sátira do modelo de mulher propagado pela reportagem da revista Veja. Os memes ainda carregam uma forte crítica aos padrões de beleza e comportamentos associados à mulher, recriando uma nova forma de expressão que rechaça esses padrões.

Eixo 3 - Atividades com produção: Outra abordagem em mídia-educação relevante seria colocar os indivíduos como produtores de mídia, mas em situações da cultura midiática para que conheçam o contexto de produção. Por exemplo, pode-se formar uma equipe com os alunos da EJA para elaboração de memes sobre questões de seu contexto social ou dia a dia, usando o laboratório de informática. Os memes podem ser criados a partir do software gratuito Paint, da Microsoft, ou mesmo por meio do site https://www.gerarmemes.com.br/. As imagens dos memes e os textos podem ser criados pelos próprios alunos.

Ao fazer isso, estamos desenvolvendo as técnicas de produção e os conceitos-chaves de linguagens midiáticas, audiência e representação (BUCKINGHAM, 2003). No caso, os alunos podem eleger temas comuns de seu cotidiano, que são representados de maneira estereotipada pela mídia. Eles terão que produzir memes fazendo uma sátira da situação ou do assunto. Terão que pensar na audiência que pretendem atingir e na representação de mundo que o meme pretende promover. Aqui são trabalhadas habilidades transmídia e multimodais, tidas como essenciais para participação efetiva na cultura digital, de acordo com Jenkins (2009). 
O professor pode finalizar a atividade expondo os memes produzidos pelos alunos. Podese analisar como cada aluno elaborou uma sátira a assuntos relacionados ao contexto deles, e que elementos da linguagem foram usados para isso, qual audiência eles pretendiam alcançar e por que, e quais os valores e visões de mundo associados aos memes produzidos por eles.

\section{Considerações finais}

A partir da discussão sobre a importância de tomar a mídia como objeto de estudo em sala de aula, pensou-se em três abordagens que promovessem a leitura crítica dos conteúdos e também habilidades multimodais e de produção de conteúdo na EJA.

Todas as abordagens visam desenvolver um olhar mais crítico sobre os diversos conteúdos midiáticos que circulam no dia a dia, e que fazem referência a temas os quais influenciam visões de mundo de jovens, adultos e idosos.

Ao explorar os conceitos-chave, trabalha-se com a ideia que os emissores fazem da audiência e como os elementos da linguagem possuem significados que muitas vezes repercutem em estereótipos. Ou seja, as abordagens não visam somente trabalhar a mídia como instrumento de apoio à aprendizagem das disciplinas, como ocorre na maioria das vezes.

Assim, as atividades com as linguagens midiáticas e a cultura digital promovem um olhar com mais autonomia, mais crítico e reflexivo para esses conteúdos. Na escolarização de jovens e adultos essa educação ganha contornos especiais, pois, apesar desses alunos estarem retornando à escola, sendo que muitos precisaram abandonar os estudos, o contato com os conteúdos da mídia são pilar central na vida desses sujeitos - eles têm contato diário com a televisão, as mídias sociais, os jornais etc. Além de aprender a ler e escrever, esses alunos podem também ser incluídos em práticas pedagógicas que visem à alfabetização das imagens, das linguagens da mídia e da contemporaneidade. Participar da cultura midiática e digital é essencial para esses alunos, que frequentemente relacionam mídia ao seu lazer, somente. Isso reflete a ausência de habilidades para compreender os conteúdos de maneira mais crítica.

Assim, a proposta é que se forme um olhar mais aguçado em torno de campanhas publicitárias, filmes, conteúdos digitais, matérias jornalísticas etc. quanto aos elementos que compõem as mensagens. 
A proposta de mídia-educação visa incluir jovens e adultos no universo de diversidade de plataformas de mídias. Combinar a análise de conteúdos midiáticos ajuda a entender que cada mídia possui um potencial para contar uma história, e que cada linguagem/conteúdo pode causar efeitos diferentes na audiência.

E, finalmente, alunos da EJA podem produzir suas próprias mensagens se utilizando das tecnologias e linguagens digitais, dentro de uma concepção que desenvolve várias habilidades desde trabalho em equipe até a criatividade.

Todas essas atividades favorecem um projeto de uma escola e EJA mais antenados quanto às necessidades do mundo atual - que é a formação crítica, cidadã e participativa em meio à cultura digital e midiática. Espera-se que a proposta possa inspirar trabalhos aplicados na área que não se limitem apenas em levar a mídia para sala de aula visando unicamente transmitir ou ilustrar conteúdos.

\section{Referências}

ALMEIDA, L. B. C. Conceitos-chave e estratégias pedagógicas: material para mídia-educação. Edu comunicando, Bauru, 2009. Disponível em: https://ligiabeatriz.wordpress.com/conceitoschave-e-estrategias-pedagogicas/. Acesso em: 20 ago. 2019.

ANSTEY, M; BULL; G. Tiempos cambiantes, alfabetizaciones cambiantes. Lectura y Vida: Revista latinoamericana de lectura, v.28, n.1, 2007, p.42-47. Disponível em: https://dialnet.unirioja.es/servlet/articulo?codigo=2281332. Acesso em: 10 fev.2017.

BÉVORT, E.; BELLONI, M. L. Mídia-educação: conceitos, história e perspectivas. Educação e Sociedade, Campinas, v.30, n.109, p. 1081-1102, set./dez. 2009.

BRASIL. Ministério da Educação. Secretaria de Educação Básica. Secretaria de Educação Continuada, Alfabetização, Diversidade e Inclusão. Diretrizes Curriculares Nacionais Gerais da Educação Básica. Brasília: MEC, SEB, DICEI, 2013.

BUCKINGHAM, D. Media education - literacy, learning and contemporary culture. Cambridge: Polity Press, 2003.

BUCKINGHAM, D. Defining digital literacy: what do young people need to know about digital media? In: LANKSHEAR, C.; KNOBEL, M. (eds.). Digital literacies. New York: Peter Lang, 2008, p 21-34

BUCKINGHAM, D. The media education manisfesto. Cambridge: Polity Press, 2019. 
GREEN, H.; HANNON, C. Their space - education for a digital generation. Londres: Demos, 2007.

HADDAD, S.; DI PIERRO, M. C. Escolarização de jovens e adultos. Revista Brasileira de Educação, Rio de Janeiro, n.14, p.108-130, mai-ago 2000. Disponível em:

https://www.scielo.br/scielo.php?pid=S1413-24782000000200007\&script=sci_abstract\&tlng=pt. Acesso em: 10 jun.2020.

HALL, S. Da diáspora. Belo Horizonte, Editora UFMG, 2003.

HALL, S.; WHANNEL, P. The popular arts. Londres: Hutchinson Educational, 1964.

FANTIN, M. Contextos, perspectivas e desafios da mídia-educação no Brasil. In: ELEÁ, I. (org.). Agentes e vozes: um panorama da mídia-educação no Brasil, Portugal e Espanha. Götenburg: Nordicon, 2014, p.49-57.

FREIRE, P. Conscientização: teoria e prática da libertação - uma introdução ao pensamento de Paulo Freire. 3.ed. São Paulo: Moraes, 1980.

FREIRE, P. Pedagogia da autonomia: saberes necessários à prática educativa. 15.ed. São Paulo: Paz e Terra, 2000.

JENKINS, H. Cultura da convergência. São Paulo: Aleph, 2009.

$\mathrm{KIRSCH}, \mathrm{M}$. B. A influência das mídias na educação de jovens e adultos e as práticas pedagógicas. 2010. 35f. TCC (Graduação em Pedagogia) - Universidade Federal do Rio Grande do Sul, Alvorada, 2010. Disponível em:

https://lume.ufrgs.br/bitstream/handle/10183/71896/000880423.pdf?sequence=1\&isAllowed=y. Acesso em: 10 jan.2019.

LEMOS, A. A crítica da crítica essencialista da cibercultura. Matrizes, v.9, n.1, p.29-51, 2015. Disponível em: http://www.matrizes.usp.br/index.php/matrizes/article/view/575/pdf_3. Acesso em: 9 dez de 2017.

LUSTED, D. Introduction. In: LUSTED, D. (org.). The media studies book - a guide for teachers. Londres: Routledge, 1991, p.01-11.

SIQUEIRA, A. B. Mídia-educação a serviço da cidadania: uma proposta para a formação de assistentes sociais. In MACEDO, A. X. N., PIRES, D. U. B. S.; ANJOS, F. A. (org.). Educação para a mídia - cadernos de debate da classificação indicativa. Brasília: Ministério da Justiça/ Secretaria Nacional de Justiça, 2014. p. 53-68

TREVISAN, M. K.; GOETHEL, M. F. Meme: intertextualidades e apropriações na Internet. In: ENCONTRO NACIONAL DE HISTÓRIA DE MÍDIA - ALCAR, 10., 2015, Porto Alegre. Anais [...]. Porto Alegre, 2015. p.01-15. 
Recebido em fevereiro 2020.

Aprovado em junho 2020. 